\title{
Eliciting Forgiveness
}

\author{
Meltem Yucel \\ University of Virginia, Psychology Department, Charlottesville (VA), USA
}

Amrisha Vaish*

University of Virginia, Psychology Department, Charlottesville (VA), USA

Forthcoming

WIREs Cognitive Science

${ }^{*}$ Correspondence concerning this article should be addressed to Amrisha Vaish,

Department of Psychology, University of Virginia, West Complex, CDW 2574, Charlottesville, VA 22903, USA. Email: vaish@virginia.edu 


\section{Abstract}

When we commit transgressions, we need to be forgiven to restore our friendships and social standing. Two main ways we can elicit forgiveness is through asking for forgiveness after committing a transgression (i.e., retrospective elicitors) or before committing a transgression (i.e., prospective elicitors). Research on retrospective elicitors with adults and children indicates that apologizing or showing remorse elicits forgiveness from both victims and bystanders, and sheds light on the nuances of such elicitors and their functions. Far less is known about how adults and children respond to prospective elicitors of forgiveness, such as disclaimers (statements that prepare the listener for a transgression or a failure of character or performance, e.g., "I don't mean to be rude but..."), and how the functions and effectiveness of prospective elicitors compare to those of retrospective elicitors. Furthermore, much less is known about the additive effects of using both retrospective and prospective elicitors of forgiveness. A better understanding how and when forgiveness is elicited in childhood and through adulthood promises to shed light on human sociality and cooperativeness. 


\section{ELICITING FORGIVENESS}

Prospective Elicitors

Asking for

forgiveness $\underline{\text { before }}$

committing a

transgression.

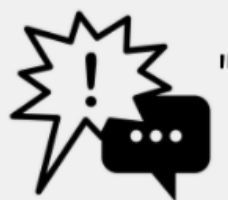

I don't mean to be rude but..."
Retrospective Elicitors

Asking for

forgiveness after committing a transgression.

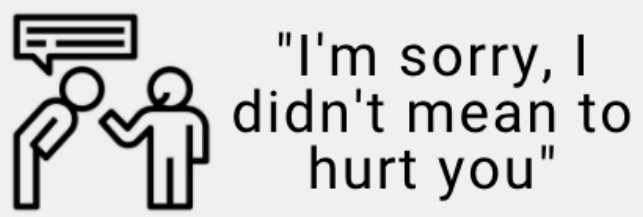

Caption: Children and adults can elicit forgiveness by either prospectively or retrospectively asking for forgiveness. 


\section{INTRODUCTION}

Over the course of evolution, humans have become ever more interdependent: We rely deeply on one another to survive and succeed, such as by exchanging goods and services, coordinating efforts to obtain food, group defense, and so forth (Tomasello, 2009). Thus, when our cooperative relationships are damaged by transgressions, as inevitably happens on occasion, it is vital that we repair them in order to continue receiving their enormous benefits. One key to this repair is forgiveness, or a "prosocial change toward a perceived transgressor" (McCullough et al., 2000, p. 9). Forgiveness fosters reconciliation and allows transgressors to reenter mutually beneficial relationships, thus helping to maintain cooperation (McCullough, 2008). Repairing ruptured cooperative relationships, therefore, rests heavily on eliciting forgiveness from victims.

Critical questions thus arise: How do transgressors elicit forgiveness? That is, what do victims respond to with forgiveness, and why? And just as importantly, when in development do individuals begin to show these patterns of forgiveness? Understanding how and when forgiveness develops will help us map out its building blocks and better understand the final product. We thus aim here to address these questions about forgiveness elicitors, with a focus on those facets that have been studied in both adults and children.

We begin by reviewing the fairly extensive literature on 'retrospective' elicitors wherein transgressors ask for forgiveness after committing a transgression (such as by apologizing). We then consider a new and thus far under-researched aspect of making amends: prospective elicitors wherein transgressors ask for forgiveness before committing a transgression. Such prospective elicitors of forgiveness may include disclaimers for failures of traits (e.g., "I'm not lazy/arrogant/selfish but..."), attitudes (e.g., "I don't mean to be rude/racist but..."), or performance (e.g., "I think I'll do poorly in this race because I sprained my ankle"). For instance, in the context of sexist discourse, speakers may say, "I'm not sexist but..." before sharing a potentially offensive view, so as to lessen the negative social repercussions of holding and sharing that view. We propose that such prospective elicitors may also elicit forgiveness from the listener(s) and mitigate damage to the reputation and relationships of the transgressor. 


\section{ELICITING FORGIVENESS}

\subsection{Retrospective elicitors}

When we think about forgiveness and its elicitors, the prototypical situation that springs to mind is likely that of a transgressor causing harm or offense to a victim and subsequently asking for forgiveness, such as by apologizing or otherwise making amends. Indeed, these are precisely the kinds of 'retrospective elicitors' that most forgiveness research has focused on. In this section, we review how adults and children use retrospective elicitors of forgiveness.

Perhaps the primary and most efficacious elicitor of forgiveness is transgressors' remorse (and apologies as a stand-in for remorse) (McCullough, 2008). Remorse indicates to the victim and other observers that the transgressor did not intend to cause harm and is also suffering from their actions. This, in turn, elicits forgiveness and sympathy from the victim or other group members and reduces the likelihood of punishment (Keltner \& Anderson, 2000; Leary et al., 1996). Furthermore, by showing remorse, transgressors signal that they are aware of and committed to the norms of the group, and so the transgression is a one-time incident rather than a personality trait (Castelfranchi \& Poggi, 2010; Goffman, 1967; Keltner et al., 1997). It stands to reason that displaying remorse is extremely effective in eliciting forgiveness from victims, and thus in repairing relationships (see Table 1).

These ideas are strongly supported in studies with adults. Research shows that what adult victims desire most from their offenders are apologies (see Petrucci, 2002). Moreover, apologies and other displays of remorse from offenders do serve to appease victims and bystanders (Fehr et al., 2010; O’Malley \& Greenberg, 1983; Ohbuchi et al., 1989). For instance, adults who read scenarios depicting a harmful accident judged the harm-doers to have partially vindicated themselves if they showed remorse, and thus stated that remorseful harm-doers needed to make fewer reparations to a victim than non-remorseful harm-doers (O'Malley \& Greenberg, 1983). Similarly, undergraduate students who were psychologically harmed by another student refrained from severe aggression against the harm-doer if the harm-doer apologized (Ohbuchi et al., 1989). These effects are longlasting: Apologizing after a transgression was found to decrease the victim's anger at the transgressor, increase the victim's perceived relationship value, and elicit forgiveness even several weeks after the transgression (McCullough et al., 2014). These results provide evidence of the power 
of remorse to appease victims and bystanders, reduce aggression toward transgressors, and repair relationships; they thus demonstrate the critical role of remorse in forgiveness.

Researchers have also increasingly been examining when and how forgiveness is elicited in children. One prominent approach utilizes a cognitive-developmental model to examine how reasoning about forgiveness changes over the course of adolescence, due in large part to the significant cognitive advances that occur over this period (Enright et al., 1989, 1992). Although this work is invaluable, its focus on adolescents' explicit reasoning about forgiveness has precluded the possibility of examining forgiveness in younger children whose verbal and reasoning skills are limited and who may instead demonstrate more basic and implicit forms of forgiveness (cf. Vaish \& Tomasello, 2014).

More recent research, emerging from a functionalist perspective on early development, has examined this possibility. This work demonstrates that transgressors' displays of remorse effectively elicit forgiveness as early as the preschool years. When children hear hypothetical stories or watch videos of transgressions, 4- to 8-year-old children blame and punish transgressors less, and forgive and like them more, if they apologized than if they did not apologize (Darby \& Schlenker, 1982; Vaish, Carpenter, et al., 2011; Wellman et al., 1979). Children also attribute improved feelings to a victim who received an apology (C. E. Smith et al., 2010). Very similar findings emerge when children are themselves the victims of transgressions. For example, when 4- and 5-year-old children suffer a transgression (e.g., someone accidentally destroys their artwork), they are more forgiving of a transgressor who shows remorse than one who does not. This is evident in children's preference for, positive evaluation of, and greater distribution of resources to the remorseful than the unremorseful transgressor (Drell \& Jaswal, 2016; Oostenbroek \& Vaish, 2019). Apologies do this work at least in part by modifying children's intention attributions such that transgressors who apologize are seen as having been less intentional in their transgressions (Ohbuchi \& Sato, 1994; Ronfard \& Lane, 2018).

Although any type of apology seems to elicit more forgiveness than no apology at all, the content of the apology does matter (Jeter \& Brannon, 2018). Among adults, on average, apologies that offer compensation (to rectify the transgression) are found to elicit the greatest level of forgiveness from the victims (Jeter \& Brannon, 2018). The content of the apology also matters to children. For instance, at age 4, children's forgiveness seems to rely on conventional elicitors of 
remorse such as explicit apologies (e.g., "I'm sorry"), whereas by age 5, children respond with forgiveness to displays of remorse even in the absence of explicit apologies (Oostenbroek \& Vaish, 2019; Vaish, Carpenter, et al., 2011). Further, 6-year-olds distinguish between different forms of apologies and respond more favorably to standard apologies (e.g., "I'm sorry, I feel badly about this") than perfunctory apologies (e.g., only saying "Excuse me") (Darby \& Schlenker, 1982). But like adults, children also prefer any type of apology (perfunctory or standard) to no apology at all (Darby \& Schlenker, 1982; though also see Drell \& Jaswal, 2016).

Transgressors' intentions also play an important role in forgiveness because intentional actions (those that willfully or knowingly cause harm) imply ill will or indifference to the victim's welfare. Indeed, adults are far less forgiving of intentional transgressions than accidental ones (Fehr et al., 2010). Moreover, adult victims who think that the transgressor purposefully caused them harm expect the transgressor to have a lower desire to be forgiven (Adams \& Inesi, 2016). Similar effects are seen among children. Young school-age children blame transgressors more and forgive them less when the transgression was intentional (Darby \& Schlenker, 1989; Ohbuchi \& Sato, 1994). Further, although both younger and older children are less forgiving of intentional transgressions, they differ in their responses to accidental transgressions such that older children are more forgiving of accidental transgressions than younger children (Amir et al., 2021).

Interestingly, intention attributions and remorse may interact in surprising ways. Among adults, apologies that follow intentional transgressions can have the ironic effect of impeding forgiveness such that intentional transgressors who apologize are forgiven less than those who do not apologize (Struthers et al., 2008). This finding is thought to reflect the conflict between the function of an apology, which is at least in part to indicate that the transgressor did not mean to cause harm and is not generally a harmful person, and the transgression itself, which was, in fact, intentionally harmful (Struthers et al., 2008). However, research with children has produced mixed results on this front. In some studies, the intentionality of transgressions (by accident vs. on purpose) affected the effectiveness of different types of apologies (perfunctory, standard, or compensation) (Darby \& Schlenker, 1982). For example, only for accidental transgressions (but not for intentional transgressions), apologies that were more elaborate were also more effective in eliciting forgiveness (Darby \& Schlenker, 1982). Yet, a more recent study found no interaction between intention 
attributions and remorse (Amir et al., 2021). The contrasting findings across these studies could partially be explained by differences in the way forgiveness was measured across studies. In work by Darby and Schlenker (1982), children were presented with hypothetical vignettes and were asked to report on whether and how much the transgressor should be forgiven, whereas in the study by Amir et al. (2021), children experienced the transgression first-hand and were asked to decide whether to discard a resource or to pass it on to the transgressor. It is possible that children respond differently to transgressors' intentions when they are themselves the victims of the transgression versus uninvolved observers (e.g., they may place less weight on the remorse when they are the victims of intentional harm), or when forgiveness is assessed using behavioral versus verbal measures. This proposed interaction between intentions, remorse, and victim deserves further attention.

With age, children also begin to recognize strategic uses of forgiveness elicitors and to distinguish when transgressors may be asking for forgiveness based on ulterior motives rather than genuinely reparative ones. One study showed, for instance, that 10-year-olds consider those who apologized privately as nicer than those who apologized publicly, arguably because public apologies help save face and uphold one's reputation among observers whereas private apologies do not (Drell et al., 2017). Another study found that 6-year-olds responded more forgivingly to apologies from their younger siblings when the apologies were unprompted rather than solicited by their parents (Schleien et al., 2010). Thus, children are not blindly appeased by all remorse displays; rather, they are savvy to the sincerity of the remorse and thus to the extent to which the remorseful transgressor is (or is not) truly committed to repairing the ruptures in the relationship.

In summary, retrospective elicitors of forgiveness such as showing remorse, making excuses, or offering reparations serve key functions in repairing ruptures after transgressions and thus facilitating group living and cooperation. A great deal of research shows that forgiveness in response to these retrospective elicitors emerges during the preschool years, when children begin to engage in collaborative relationships that they are motivated to maintain (Dunn, 2004), and that with age, children become more sophisticated and flexible forgivers.

Important and fascinating questions still remain open. One question that arises is how social relationships factor into the effectiveness of retrospective elicitors. For instance, how does remorse interact with the relationship between victim and transgressor? One proposal in this regard is the 
valuable relationship hypothesis, according to which close and committed relationship partners more readily forgive each other because forgiveness is an effective means of achieving the victims' primary goal: to remain in the relationship (Finkel et al., 2002; also see McCullough, 2008). Indeed, among adults, relationship closeness and commitment are related positively to forgiveness (see Burnette et al., 2012; Fehr et al., 2010). For instance, lack of forgiveness in committed relationships leads to greater anxiety and negative emotions than forgiveness, whereas this difference is not apparent in non-committed relationships (Karremans et al., 2003). Furthermore, when making decisions to forgive, perceptions of relationship value (i.e., how important the relationship is for me) and exploitation risk (i.e., would the person take advantage of me) factor into their decisions (Burnette et al., 2012). Though there seem to be cross-cultural differences in how relationship value and exploitation risk may interact (A. Smith et al., 2020), this body of work suggests that at least among adults, forgiveness may be especially important and most effectively elicited in committed relationships. Although the impact of relationship closeness on forgiveness has not yet been examined among young children, we expect that similar patterns may emerge, namely, that even among young children, valuable relationship partners may elicit greater forgiveness than non-valuable partners or strangers.

Another unknown in development is how individual or cultural factors relate to the ways in which forgiveness is elicited and shaped in children. Among adults, different types of apologies are differently effective depending on the victim's construal of themselves. For example, victims who construe their selves in relation to others evaluate apologies that express empathy to be more effective than apologies that refer to compensation or norms, whereas victims who have an independent self-construal evaluate apologies that involve compensation to be more effective than apologies that refer to norms or empathy (Fehr \& Gelfand, 2010). No such comparisons exist with children. More generally, far more research is needed to understand how individual factors (such as self-construal or temperament), socialization, and cultural influences impact the effectiveness of retrospective elicitors of forgiveness.

\subsection{Prospective elicitors}

We have learned a great deal over the past several decades about retrospective elicitors of forgiveness and their functions in both adults and children. On the other hand, far less attention has 
been paid to forgiveness elicitors before committing transgressions, i.e., prospective elicitors. For current purposes, we will focus on one type of prospective elicitors: disclaimers. Disclaimers are a "verbal device employed to ward off and defeat in advance doubts and negative typifications which may result from intended conduct" (Hewitt \& Stokes, 1975, p.3) that are often structured as "not X or anything, but Y" (Overstreet \& Yule, 2001, p. 45). Disclaimers can excuse failures of traits (e.g., "I'm not lazy/selfish but..."), attitudes (e.g., "I'm not racist but"), or performance (e.g., "[l may play] not that well today because last night I tripped and hurt my foot”) (El-Alayli et al., 2008; Watling \& Banerjee, 2012).

In what follows, we first describe when adults use disclaimers and what proposed functions these disclaimers serve. We then describe what little is known about children's understanding of and responses to disclaimers. Throughout, we make suggestions for future work in this area. In particular, we aim to bring more attention to the limited research on the functions of prospective elicitors among children. By looking at how children respond to disclaimers, we expect to get a better understanding of the early cooperative function of prospective elicitors.

Unlike apologies and excuses, disclaimers are primarily thought to help the transgressor to save face by pre-emptively avoiding damage to their social relationships and to protect their reputation prior to committing a transgression (Hewitt \& Stokes, 1975; though their reputational benefits have also been challenged by Bell et al., 1984). For instance, some prior studies with adults have examined the use of disclaimers in the context of racial discourse (e.g., "I'm not a racist but...") (Bonilla-Silva \& Forman, 2000; van Dijk, 1992b). People often resort to such disclaimers in an attempt to adhere to the social norm and not appear racist (Bonilla-Silva \& Forman, 2000; van Dijk, 1992b). These types of statements are argued to serve the function of pre-emptively denying that the speaker is racist to avoid risking the speaker's relationships and reputation (Hewitt \& Stokes, 1975).

Though researchers have mostly focused on speakers' use of disclaimers rather than on listeners' reactions to them, it has been argued that listeners can either fully or partially accept disclaimers or reject them. Hewitt and Stokes (1975) argue that in the best-case scenario, the listener will fully accept the disclaimer and think that the speaker is not a racist and has a good point. In cases when the listener partially accepts the disclaimer, yet does not agree with the speaker's argument, the listener will still think that the speaker is not a racist (Hewitt \& Stokes, 1975). 
We suggest augmenting this proposal. Specifically, we submit that disclaimers allow the speaker to hedge their bets when they hope to find new common ground with the listener but cannot know with confidence whether the listener will be offended by or agree with their opinion. Assuming the listener accepts the disclaimer, the listener may in fact respond by agreeing with the speaker, thus allowing them to find new common ground in their views. Indeed, that may be part of the speaker's goal in offering their potentially offensive view in the first place: to align views - and thus form a closer connection with - the speaker. However, if the listener does take offense at the statement, the speaker has nonetheless pre-emptively protected their reputation and relationship through the disclaimer. Note that this is an important distinction between prospective and retrospective elicitors: When the speaker cannot confidently predict how their act will be received, prospective elicitors offer the speaker a cautious strategy to finding new common ground and a closer connection with the listener while still protecting against the risk of causing too much damage. Nonetheless, there remains the possibility that the listener will not accept the disclaimer and will take offense, thus damaging the relationship and reputation of the speaker; in such cases, the disclaimer has not worked as a prospective elicitor of forgiveness and the speaker must then rely on retrospective elicitors if they seek to mend the rupture.

Furthermore, much like asking for forgiveness after transgressions, asking for forgiveness before transgressions may also serve multiple functions. For instance, in addition to managing one's reputation, disclaimers may also serve as a warning for conversation partners to prepare themselves for a transgression. The speaker can then mitigate the negative impact of their harmful behavior and decrease the need for eliciting forgiveness after the fact. In other words, disclaimers may prepare the recipient for something offensive or non-normative by dampening the shock of the transgression, which could reduce the recipient's negative response to the transgressor (Hewitt \& Stokes, 1975; van Dijk, 1992a), thus shortening the recipient's path to forgiveness and reducing the punishment that they mete out to the transgressor.

Another way in which disclaiming can help reduce the recipient's negative response to the transgressor is by allowing the listener to separate the act (e.g., a sexist statement) from the actor (i.e., transgressor). In other words, by using disclaimers such as "I'm not a sexist but...," the speaker is signaling that this one offensive statement they are about to make or view they hold does not reflect 
more generally on them as a person. As an example, in many cultures, gossip is seen as a negative trait (Zinovieff, 1991). By disclaiming prior to gossiping (e.g., "I do not like to gossip, but ..."), gossipers can signal that this instance of gossiping is not indicative of the gossiper's character and, therefore, manage their reputation of not being a gossip. In one reported instance, "I don't like gossip but don't you know that Susana last night was walking around..." (Hall, 1994, p.7) indicated the gossiper's desire to share important information about the victim of gossip (Susana) with her friend (the bystander), while also attempting to avoid the "gossip" label. In this way, disclaimers may be similar to apologies, which also signal that the transgression was a one-time incident rather than a personality trait and that the transgressor is otherwise a good, norm-following group member (Castelfranchi \& Poggi, 2010; Goffman, 1967; Keltner et al., 1997).

Finally, disclaimers can even be used when there are no victims at all (e.g., disclaiming one's poor performance). Though victimless, these instances can nonetheless be considered transgressions of sorts - or at least violations of expectation that can damage the speaker's reputation. We propose that disclaimers in such contexts may still serve reputation-management functions, such as by preparing the listener for the poor performance and thereby dampening its negative impact, as well as by encouraging the listener to distinguish this one poor performance from the actor as a whole. These are tentative proposals, however. Systematic research is needed on the impacts of disclaiming victimless transgressions and on whether these impacts are similar to or distinct from the impacts of disclaiming transgressions that directly or indirectly involve victims.

More generally, much of our knowledge of this topic is currently limited to sociological and anthropological analyses of disclaimers, such as the contexts in which people use disclaimers or the presumed reasons they do so. Yet, these analyses have not examined how disclaimers affect the listener and their relationship with or their perceptions of the speaker. Furthermore, there has been minimal focus on their psychological impacts and whether and how disclaimers may facilitate forgiveness. These will all be fascinating and vital new directions for future work.

Equally importantly, almost no work exists on children's responses to disclaimers about transgressions. The very limited research has focused entirely on disclaimers of failure to perform (Bennett, 1990; Watling \& Banerjee, 2012). In one study, children heard a vignette of a protagonist who is asked to help with a task. The protagonist either disclaimed (e.g., "I am not very good at 
washing dishes") or did not disclaim before failing at the task (e.g., dropping the plate). Five-year-olds thought the protagonist deserved punishment regardless of his use of disclaimers. However, 11-yearolds thought the protagonist deserved less punishment if he had disclaimed his failure beforehand. Though younger children's punishment decisions were not impacted by the use of disclaimers, their justifications for their decision not to punish the protagonist showed that about half of 8-year-olds and a quarter of 5-year-olds did consider the mitigating functions of disclaimers. Thus, by the early school years and more robustly during middle childhood, children begin to develop an understanding of the purpose of disclaiming, namely, as a warning mechanism for the listener to lower their expectations and excuse the protagonist's failure to perform well (Bennett, 1990).

Although this first study did not specifically assess the reputation management functions of disclaimers, a more recent study found some support for this function by late in middle childhood. Specifically, the researchers found that while 7-year-olds were unaffected by disclaimers, children 10 to 14 years of age understood that disclaiming poor performance might serve to protect the protagonists' reputation (Watling \& Banerjee, 2012). Moreover, older children believed that protagonists who disclaim might be judged less harshly by the audience (Watling \& Banerjee, 2012). These findings suggest that children develop an understanding of the reputational functions of disclaimers around the age of 10 .

Note, however, that the protagonists in Watling and Banerjee's (2012) study disclaimed their performance not just in the experimental condition (e.g., "No, I do not think I will win this match because my arm is a bit sore today") but also in the control condition (e.g., "No, I do not think I will win this match"). In other words, both conditions involved varying levels of disclaimers - either with or without additional justifications. Thus, although the authors interpret their findings as showing that children understand disclaimers about performance, their study, in fact, addressed differences in children's responses to disclaimers with or without justifications. A critical comparison between no disclaimers and disclaimers is needed to better understand the functions of disclaimers in childhood. Further, neither of the studies mentioned above, and indeed no existing studies, have compared disclaimers to retrospective elicitors in terms of their effectiveness for eliciting forgiveness. We thus do not yet know whether prospective and retrospective elicitors serve the same or different functions. It is possible that both prospective and retrospective elicitors manage one's reputation and 
repair relationships to the same degree. However, it is also plausible that retrospective elicitors may be better at eliciting forgiveness than prospective elicitors. If it is the case, as we propose, that prospective elicitors dampen the expectations of listeners and decrease the perception of a transgression, then prospective elicitors may, in fact, reduce the amount of forgiveness that must be elicited in the first place. We may thus ask: Which is the more effective forgiveness elicitor: disclaiming before a transgression or apologizing after the transgression? Or is it better to do both? One benefit of using both prospective and retrospective elicitors is that they may offer two levels of protection from damaging one's relationships. For example, in the case that the disclaimer is rejected, the speaker can still apologize, repair the damage, and save face. These questions also give rise to potential developmental changes or differences among younger and older children and adults. Is one kind of elicitor more effective with children and the other increasingly effective with age? Such questions will be fascinating to explore in future work.

Interesting developmental predictions also emerge from the fact that the use of disclaimers likely requires many additional socio-cognitive capacities that the use of apologies may not. To preemptively disclaim a transgression, one must at least grasp: 1) that the statement or action one is about to produce is considered a transgression or at least frowned upon (a reflective understanding of social norms), 2) that the statement or action may cause offense and may hurt one's relationships and/or reputation (anticipatory perspective-taking and prospective thinking more generally), and 3) that in order to mitigate the damage, one ought to provide a disclaimer before producing the statement or action (inhibiting impulsive behavior and exercising self-regulation). Retrospective elicitors such as apologies likely do not require such advanced socio-cognitive capacities. A young child may impulsively hit her friend to get her toy back, only to later realize that her actions hurt her friend (often in response to the friend showing distress) and to then apologize and make amends. In such situations, the child need not reflect on the physical or social harm her actions will cause or selfregulate to mitigate that harm before engaging in the action.

This key distinction leads to the prediction that the use of disclaimers should emerge later in development (when these advanced socio-cognitive capacities are more robust) than the use of apologies. Initial support for this proposal comes from findings (reviewed earlier) that children consider a speaker's disclaimer use and appreciate its social functions only by around 10 to 11 years 
of age (Bennett, 1990; Watling \& Banerjee, 2012), whereas children begin to consider a

transgressor's apologies as early as 4 to 5 years of age (e.g., Smith et al., 2010; Vaish et al., 2011). Therefore, far more research is needed to understand the socio-cognitive capacities required to use prospective and retrospective elicitors in order to better understand their developmental emergence and underlying mechanisms.

Many other interesting avenues remain open. First, there has been no work investigating whether adults perceive disclaimers to serve different functions (perhaps depending on context) and if so, when in development children begin to understand these different functions. One question in this regard is whether disclaimers about different domains (traits, attitudes, norms) serve similar or distinct functions in development. Given that even very young children are motivated to maintain cooperation through following and enforcing norms (Schmidt \& Tomasello, 2012; Vaish, Missana, et al., 2011; Yucel \& Vaish, 2018), it is possible that younger children may respond to norm-based disclaimers before trait or attitude based disclaimers with forgiveness. On the other hand, even infants show rudimentary trait evaluations of characters as nice or mean (see Hamlin, 2013; Van de Vondervoort \& Hamlin, 2018), and may therefore respond to trait-based disclaimers before norm- or attitude-based disclaimers.

It will also be interesting to investigate whether disclaimers work equally well for all kinds of transgressions. For instance, are they equally useful for minor transgressions (e.g., making rude comments about others) and for major transgressions (e.g., racist comments), or is disclaiming perhaps insufficient when the impending transgression is egregious? Relatedly, are disclaimers just as effective for moral transgressions (those that cause harm) as for conventional transgressions (those that disrupt social coordination but do not harm anyone) (Smetana et al., 2014; Yucel et al., 2020)? Finally, all of these questions about understanding the functions of disclaimers must be addressed alongside research on when children begin to use disclaimers themselves, in which contexts, and how that changes during development and into adulthood. In sum, although retrospective elicitors of forgiveness have received a great deal of attention, far more research is needed to understand what functions are served when people prospectively disclaim their transgressions and at what age we become sensitive to these signals. 
Figures and Tables

Table 1

\begin{tabular}{|c|c|c|c|c|c|}
\hline \multicolumn{2}{|c|}{ Functions } & \multicolumn{4}{|c|}{ Elicitors used } \\
\hline & & No elicitors & Only prospective elicitors & Only retrospective elicitors & $\begin{array}{c}\text { Both prospective and retrospective } \\
\text { elicitors }\end{array}$ \\
\hline \multirow[t]{2}{*}{ Relationship } & Impact & Damages relationships & $\begin{array}{l}\text { Mitigates damage to the } \\
\text { relationship }\end{array}$ & $\begin{array}{l}\text { Repairs damage to the } \\
\text { relationship }\end{array}$ & $\begin{array}{l}\text { Mitigates and repairs damage to } \\
\text { the relationship }\end{array}$ \\
\hline & Evidence & Present in children and adults & $\begin{array}{l}\text { Present in adults. } \\
\text { Needed with children }\end{array}$ & Present in children and adults & Needed \\
\hline \multirow[t]{2}{*}{ Reputation } & Impact & Damages reputation & $\begin{array}{l}\text { Mitigates damage to the } \\
\text { reputation }\end{array}$ & $\begin{array}{l}\text { Repairs damage to the } \\
\text { reputation }\end{array}$ & $\begin{array}{l}\text { Mitigates and repairs damage to } \\
\text { the relationship }\end{array}$ \\
\hline & Evidence & Present in children and adults & $\begin{array}{l}\text { Present in adults. Needed with } \\
\text { children }\end{array}$ & Shown in children and adults & Needed \\
\hline $\begin{array}{l}\text { Eliciting } \\
\text { Forgiveness }\end{array}$ & Impact & $\begin{array}{l}\text { Does not elicit forgiveness or } \\
\text { elicits less forgiveness than } \\
\text { using elicitors }\end{array}$ & $\begin{array}{l}\text { Pre-emptively elicits forgiveness } \\
\text { and/or reduces the need to elicit } \\
\text { forgiveness }\end{array}$ & $\begin{array}{l}\text { Elicits forgiveness after the } \\
\text { transgression }\end{array}$ & $\begin{array}{l}\text { Elicits forgiveness and/or reduces } \\
\text { the need to elicit forgiveness }\end{array}$ \\
\hline & Evidence & Present in children and adults & Needed & Present in children and adults & Needed \\
\hline
\end{tabular}

Note. Table compares different reputation management elicitors (no elicitor, prospective elicitors, and retrospective elicitors) and their proposed social

function 


\section{Conclusion}

From small infractions to bigger ones, we all transgress in our social interactions. What allows us to maintain our relationships and social status is partly determined by how we respond and remedy our transgressions. In order to make amends and maintain our positive reputation, we can either ask for forgiveness after committing a transgression (retrospective elicitors) or before committing a transgression (prospective elicitors). Indeed, forgiveness has become a central facilitator of long-term cooperation in our evolutionary history (McCullough, 2008, 2010). Despite its importance, elicitors of forgiveness have been understudied. Research on retrospective elicitors with adults demonstrates that apologizing or showing remorse does indeed elicit forgiveness from victims and bystanders. Importantly, even young children respond to these retrospective elicitors. Yet, many questions remain unanswered about whether prospective elicitors serve similar or distinct functions and how those functions develop over time. More importantly, much more needs to be discovered about how retrospective and prospective elicitors can work together to elicit forgiveness. Investigating these questions will expand our understanding of forgiveness and thereby shed light on human sociality and cooperativeness.

\section{Funding Information}

This work was supported by a grant from the John Templeton Foundation to Amrisha Vaish (Grant 55437).

\section{Acknowledgments}

We are extremely grateful to Drs. Erin C. Westgate, Janine Oostenbroek, and Darwin A. Guevarra for helpful discussions. 


\section{References}

Adams, G. S., \& Inesi, M. E. (2016). Impediments to forgiveness: Victim and transgressor attributions of intent and guilt. Journal of Personality and Social Psychology, 111(6), 866-881. https://doi.org/10.1037/pspi0000070

Amir, D., Ahl, R. E., Parsons, W. S., \& Mcauliffe, K. (2021). Children are more forgiving of accidental harms across development. Journal of Experimental Child Psychology, 61138. https://doi.org/10.17605/OSF.IO/M6FHW

Bell, R. A., Zahn, C. J., \& Hopper, R. (1984). Disclaiming: A test of two competing views. Communication Quarterly, 32(1), 28-36. https://doi.org/10.1080/01463378409369528

Bennett, M. (1990). Children's understanding of the mitigating function of disclaimers. Journal of Social Psychology, 130(1), 29-37. https://doi.org/10.1080/00224545.1990.9922930

Bonilla-Silva, E., \& Forman, T. A. (2000). "I am not a racist but...": Mapping White college students' racial ideology in the USA. Discourse \& Society, 11(1), 50-85.

https://doi.org/10.1177/0957926500011001003

Burnette, J. L., McCullough, M. E., van Tongeren, D. R., \& Davis, D. E. (2012). Forgiveness results from integrating information about relationship value and exploitation risk. Personality and Social Psychology Bulletin, 38(3), 345-356. https://doi.org/10.1177/0146167211424582

Castelfranchi, C., \& Poggi, I. (2010). Blushing as a discourse: Was Darwin wrong? Shyness and Embarrassment, 230-252. https://doi.org/10.1017/cbo9780511571183.009

Darby, B. W., \& Schlenker, B. R. (1982). Children's reactions to apologies. Journal of Personality and Social Psychology, 43(4), 742-753. https://doi.org/10.1037//0022-3514.43.4.742

Darby, B. W., \& Schlenker, B. R. (1989). Children's reactions to transgressions: Effects of the actor's apology, reputation and remorse. British Journal of Social Psychology, 28(4), 353-364. https://doi.org/10.1111/j.2044-8309.1989.tb00879.x

Drell, M. B., \& Jaswal, V. K. (2016). Making amends: Children's expectations about and responses to apologies. Social Development, 25(4), 742-758. https://doi.org/10.1111/sode.12168

Drell, M. B., Sampson, S., \& Jaswal, V. K. (2017, October 12-14). Children's sensitivity to the ulterior motives behind apologies [Poster]. Cognitive Development Society, Portland, Oregon. https://cogdevsoc.org/wp-content/uploads/2017/10/CDS-program-2017-104-1.pdf 
Dunn, J. (2004). Children's friendships: The beginnings of intimacy. Blackwell.

El-Alayli, A., Myers, C. J., Petersen, T. L., \& Lystad, A. L. (2008). “I don't mean to sound arrogant, but..." the effects of using disclaimers on person perception. Personality and Social Psychology Bulletin, 34(1), 130-143. https://doi.org/10.1177/0146167207309200

Enright, R. D., Gassin, E. A., \& Wu, C. (1992). Forgiveness: A developmental view. Journal of Moral Education, 21(2), 99-114. https://doi.org/10.1080/0305724920210202

Enright, R. D., Santos, M. J. D., \& Al-Mabuk, R. (1989). The adolescent as forgiver. Journal of Adolescence, 12(1), 95-110. https://doi.org/10.1016/0140-1971(89)90092-4

Fehr, R., \& Gelfand, M. J. (2010). When apologies work: How matching apology components to victims' self-construals facilitates forgiveness. Organizational Behavior and Human Decision Processes, 113(1), 37-50. https://doi.org/10.1016/j.obhdp.2010.04.002

Fehr, R., Gelfand, M. J., \& Nag, M. (2010). The road to forgiveness: A meta-analytic synthesis of its situational and dispositional correlates. Psychological Bulletin, 136(5), 894-914. https://doi.org/10.1037/a0019993

Finkel, E. J., Rusbult, C. E., Kumashiro, M., \& Hannon, P. A. (2002). Dealing with betrayal in close relationships: Does commitment promote forgiveness? Journal of Personality and Social Psychology, 82(6), 956-974. https://doi.org/10.1037/0022-3514.82.6.956

Goffman, E. (1967). Interaction ritual: Essays on face-to-face behavior. Anchor.

Hamlin, J. K. (2013). Moral judgment and action in preverbal infants and toddlers: Evidence for an innate moral core. Current Directions in Psychological Science, 22(3), 186-193. https://doi.org/10.1177/0963721412470687

Hall, J. K. (1994, September 28-October 2). The power of women's voices in the practice of "chismeando." [Paper presentation]. The Annual Meeting for the Organization for the Study of Communication, Language, and Gender, Gainesville, FL, United States.

Hewitt, J. P., \& Stokes, R. (1975). Disclaimers. American Sociological Review, 4O(1), 1-11.

Jeter, W. K., \& Brannon, L. A. (2018). 'I'll make it up to you:' Examining the effect of apologies on forgiveness. Journal of Positive Psychology, 13(6), 597-604.

https://doi.org/10.1080/17439760.2017.1291854

Karremans, J. C., Van Lange, P. A. M., Ouwerkerk, J. W., \& Kluwer, E. S. (2003). When forgiving 
enhances psychological well-being: The role of interpersonal commitment. Journal of Personality and Social Psychology, 84(5), 1011-1026. https://doi.org/10.1037/0022-3514.84.5.1011

Keltner, D., \& Anderson, C. (2000). Saving face for Darwin: The functions and uses of embarrassment. Current Directions in Psychological Science, 9(6), 187-192. https://doi.org/10.1111/1467-8721.00091

Keltner, D., Young, R. C., \& Buswell, B. N. (1997). Appeasement in human emotion, social practice, and personality. Aggressive Behavior, 23(5), 359-374. https://doi.org/10.1002/(SICl)10982337(1997)23:5<359::AID-AB5>3.0.CO;2-D

Leary, M. R., Landel, J. L., \& Patton, K. M. (1996). The motivated expression of embarrassment following a self-presentational predicament. Journal of Personality, 64(3), 619-636. https://doi.org/10.1111/j.1467-6494.1996.tb00524.x

McCullough, M. E. (2008). Beyond revenge: The evolution of the forgiveness instinct. Jossey-Bass. McCullough, M. E. (2010). The forgiveness instinct. In D. Keltner, J. Marsh, \& J. A. Smith (Eds.), The compassionate instinct: The science of human goodness. W. W. Norton \& Company, Inc.

McCullough, M. E., Pargament, K. I., \& Thoresen, C. E. (2000). Forgiveness: Theory, research, and practice. Guilford Press.

McCullough, M. E., Pedersen, E. J., Tabak, B. A., \& Carter, E. C. (2014). Conciliatory gestures promote forgiveness and reduce anger in humans. Proceedings of the National Academy of Sciences of the United States of America, 111(30), 11211-11216. https://doi.org/10.1073/pnas.1405072111

O’Malley, M. N., \& Greenberg, J. (1983). Sex differences in restoring justice: The down payment effect. Journal of Research in Personality, 17(2), 174-185. https://doi.org/10.1016/00926566(83)90029-6

Ohbuchi, K. I., Kameda, M., \& Agarie, N. (1989). Apology as aggression a control: Its role in mediating appraisal of and response to harm. Journal of Personality and Social Psychology, 56(2), 219-227. https://doi.org/10.1037/0022-3514.56.2.219

Ohbuchi, K. I., \& Sato, K. (1994). Children's reactions to mitigating accounts: Apologies, excuses, and intentionality of harm. Journal of Social Psychology, 134(1), 5-17. https://doi.org/10.1080/00224545.1994.9710877 
Oostenbroek, J., \& Vaish, A. (2019). The emergence of forgiveness in young children. Child Development, 90(6), 1969-1986. https://doi.org/10.1111/cdev.13069

Overstreet, M., \& Yule, G. (2001). Formulaic disclaimers. Journal of Pragmatics, 33(1), 45-60. https://doi.org/10.1016/S0378-2166(99)00125-3

Petrucci, C. J. (2002). Apology in the criminal justice setting: Evidence for including apology as an additional component in the legal system. Behavioral Sciences and the Law, 20(4), 337-362. https://doi.org/10.1002/bsl.495

Ronfard, S., \& Lane, J. D. (2018). Preschoolers continually adjust their epistemic trust based on an informant's ongoing accuracy. Child Development, 89(2), 414-429. https://doi.org/10.1111/cdev.12720

Schleien, S., Ross, H., \& Ross, M. (2010). Young children's apologies to their siblings. Social Development, 19(1), 170-186. https://doi.org/10.1111/j.1467-9507.2008.00526.x

Schmidt, M. F. H., \& Tomasello, M. (2012). Young children enforce social norms. Current Directions in Psychological Science, 21(4), 232-236. https://doi.org/10.1177/0963721412448659

Smetana, J. G., Jambon, M., \& Ball, C. (2014). The social domain approach to children's moral and social judgments. In M. Killen \& J. Smetana (Eds.), Handbook of moral development (2nd ed.) (pp. 23-45).

Smith, A., McCauley, T. G., Yagi, A., Yamaura, K., Shimizu, H., McCullough, M. E., \& Ohtsubo, Y. (2020). Perceived goal instrumentality is associated with forgiveness: A test of the valuable relationships hypothesis. Evolution and Human Behavior, 41(1), 58-68. https://doi.org/10.1016/j.evolhumbehav.2019.09.003

Smith, C. E., Chen, D., \& Harris, P. L. (2010). When the happy victimizer says sorry: Children's understanding of apology and emotion. British Journal of Developmental Psychology, 28(4), 727-746. https://doi.org/10.1348/026151009X475343

Struthers, C. W., Eaton, J., Santelli, A. G., Uchiyama, M., \& Shirvani, N. (2008). The effects of attributions of intent and apology on forgiveness: When saying sorry may not help the story. Journal of Experimental Social Psychology, 44(4), 983-992.

https://doi.org/10.1016/j.jesp.2008.02.006

Tomasello, M. (2009). Why we cooperate. MIT Press. 
Vaish, A., Carpenter, M., \& Tomasello, M. (2011). Young children's responses to guilt displays.

Developmental Psychology, 47(5), 1248-1262. https://doi.org/10.1037/a0024462

Vaish, A., Missana, M., \& Tomasello, M. (2011). Three-year-old children intervene in third-party moral transgressions. The British Journal of Developmental Psychology, 29(Pt 1), 124-130. https://doi.org/10.1348/026151010X532888

Vaish, A., \& Tomasello, M. (2014). The early ontogeny of human cooperation and morality. In Handbook of Moral Development, Second Edition (pp. 279-298). https://doi.org/10.4324/9780203581957

Van de Vondervoort, J. W., \& Hamlin, J. K. (2018). The early emergence of sociomoral evaluation: infants prefer prosocial others. Current Opinion in Psychology, 20, 77-81. https://doi.org/10.1016/j.copsyc.2017.08.014

van Dijk, T. A. (1992a). Denying racism: Elite discourse and racism. Discourse and Society, 3(1992), 87-118.

van Dijk, T. A. (1992b). Discourse and the denial of racism. Discourse \& Society, 3(1), 87-118. https://doi.org/10.1177/0957926592003001005

Watling, D., \& Banerjee, R. (2012). Children's understanding of disclaimers. Social Cognition, 30(1), 18-36. https://doi.org/10.1521/soco.2012.30.1.18

Wellman, H. M., Larkey, C., \& Somerville, S. C. (1979). The early development of moral criteria. Child Development, 50(3), 869. https://doi.org/10.2307/1128956

Yucel, M., Hepach, R., \& Vaish, A. (2020). Young children and adults show differential arousal to moral and conventional transgressions. Frontiers in Psychology, 11. https://doi.org/10.3389/fpsyg.2020.00548

Yucel, M., \& Vaish, A. (2018). Young children tattle to enforce moral norms. Social Development, 27(4), 924-936. https://doi.org/10.1111/sode.12290

Zinovieff, S. (1991). Inside out and outside in: Gossip, hospitality and the Greek character. Journal of Mediterranean Studies, 1, 120-134.

\section{Further Reading}

Darby, B. W., \& Schlenker, B. R. (1982). Children's reactions to apologies. Journal of Personality and 
Social Psychology, 43(4), 742-753. https://doi.org/10.1037//0022-3514.43.4.742

Darby, B. W., \& Schlenker, B. R. (1989). Children's reactions to transgressions: Effects of the actor's apology, reputation and remorse. British Journal of Social Psychology, 28(4), 353-364. https://doi.org/10.1111/j.2044-8309.1989.tb00879.x

Oostenbroek, J., \& Vaish, A. (2019). The emergence of forgiveness in young children. Child Development, 90(6), 1969-1986. https://doi.org/10.1111/cdev.13069

Watling, D., \& Banerjee, R. (2012). Children's understanding of disclaimers. Social Cognition, 30(1), 18-36. https://doi.org/10.1521/soco.2012.30.1.18 